\title{
Needs Analysis of Second Language Learners with particular regard to their Writing Skills
}

\author{
Mahrukh Baig \\ M.Phil Applied Linguistics, Lecturer English, University of Management and Technology, Lahore, Pakistan \\ M.A. English Literature, Kinnaird College for Women Lahore, Pakistan
}

\begin{abstract}
The current research study sets out to analyze the course material of the second language learners to check whether it is sufficient to cater their language needs with particular regard to writing skills. One of the major issues in development of writing skills is about learner-centeredness which raises the question: "Is it the role of students to serve academic institutions or is it the role of institutions to serve students?" The answer to this question is obviously the latter which can be implemented in all academic institutions by understanding learners' needs and getting data from them before designing the teaching materials. It is necessary to know what the learners' objectives are, what they are expecting from the course, and the characteristics of their learning habits.
\end{abstract}

Key Words: Second Language Acquisition, Middle-school language learners, Needs Analysis, Writing Skills, Role of course material in SLA

\section{Introduction}

Good writing does not just happen. The best writers spend a great deal of time thinking, planning, rewriting and editing. (Elizabeth West)

As compared to other fundamental skills such as listening, speaking and reading, writing is the most difficult one because it requires writers to have a certain amount of second language background knowledge about the expression, organization, appropriate language use or specific vocabulary with which they want to communicate to their readers.

Academic writing requires conscious effort and much practice in composing, developing, and analyzing ideas. Students' writing in a second language is also faced with social challenges related to second language acquisition such as:

1. negative attitudes toward the target language

2. continued lack of progress

3. cultural gap between L1 and L2, and,

4. lack of motivation for learners.

To highlight socio-cultural effects on writing, Omaggio (1993) states that the ability to write well is not a naturally acquired skill; it is usually learned or culturally transmitted as a set of practices in formal instructional settings or other environments. Thus, writing skills must be practiced and learned through experience. However, language proficiency and competence depends on the ability to write in the second language in a fundamental way. Therefore, L2 writing instructors should take into account both strategy development and language skill development while working with students.

\section{Hypothesis/ Research Question}

The basic question of research looks at: (a) the differences between what students think they need to learn and what their syllabus designers think the students should learn, (b) if what the teachers actually teach meets what students think they should learn, and (c) the kinds of writing problems students have and whether the teachers are aware of them or not.

\section{Objectives}

The objectives of the research project are to:

1. Gauge the writing needs of language learners enrolled in grade 7.

2. Analyze these needs with reference to the textbook being used in their classroom.

3. Explore the importance of knowing the learners' choices, to match their needs with teaching strategies.

4. Provide suggestions for improvement of the curricula in practice.

\section{Significance of the Study}

1. "Needs Analysis" does give valuable information for teachers and linguists to understand the learners' needs and attitude towards the target language. 
2. The intended use of research tools such as questionnaire and analysis of the textbook is meant to elicit the learners' linguistic needs, objectives, their available resources, and some of the instructional factors affecting their language learning, which is aimed to be achieved in the study.

3. The result of the analysis will be helpful in understanding the characteristics of the learners and will also be useful for policy makers, curriculum planners, material designers, language teachers, teacher trainers and those who are interested in the field.

\section{Justification of the Study}

Teaching writing skills to non-native students is a very challenging task for teachers because developing this skill takes a long time to see the improvement. In addition, teaching separate writing approaches in the writing class does not fit in a second language context since the weaknesses of each writing approach tend to impede students' writing development. Therefore, writing teachers need to incorporate the insights of the different approaches and apply an integrated/eclectic approach into the writing class for teaching second language learners. The strengths of one approach can complement the other. Moreover, a combination of approaches will make space for the integration of language skills automatically. It will also apply communicative techniques in the classroom and will help the teachers to develop learners' writing competence by providing appropriate input of knowledge and skills in the writing procedure.

\section{Definition of "Needs Analysis"}

There is a long history of analyzing students' language needs. All the modern studies show that needs analysis plays an important role in second language or foreign language teaching. A general definition of a Needs Analysis according to Brown (2001:272) is "the systematic collection and analysis of all relevant information that is necessary to satisfy the language learning needs of the students within the contexts of the particular institution(s)."

\section{Assumption}

The age group, intelligence quotient, cognitive ability and level of understanding of the subjects are assumed to be equal in this research.

\section{Limitation}

The researcher cannot analyze the course materials of all the language learners around the country in order to conduct their Needs Analysis.

\section{Delimitation}

The research will, therefore, be delimited to the students of one of the middle-class schools in Lahore.

\section{Literature Review}

This review of the relevant literature is organized into two main parts. The first part will provide a critical evaluation of current writing approaches, pointing out not only their benefits but also the drawbacks. Moreover, it will focus on the importance of using these approaches in an integrated manner to improve learners' writing competence in English language. The second part of literature review will be dealing with the importance of a Needs Analysis with regards to the students' second or foreign language skills. Besides the significance, it will also state the purpose, validity, reliability, limitations and methods of measuring the needs of the learners.

\section{Effective Writing:}

Abisamra (2001) states that a well-written piece can be described as incorporating elements of writing in such a way that a reader can experience the writer's intended meaning, understand his premise, and accept or reject his point of view.

Effective Writing:

- is focused on the topic and does not contain any irrelevant information;

- The document is properly formatted. It enables the reader to successfully follow the piece of writing from the beginning till the end. Transitional devices can aid the document;

- Follows the conventions of standard written English (i.e., punctuation, capitalization, and spelling). Keen eye is used while referring to the details or sub plots. Impressive or mature writing style needs to be promoted. Monotonous sentences need to be discouraged.

Critical Analysis Of Current Writing Approaches:

1- Product Approach: 
Product-based writing approaches have been called by several names: the controlled- to-free approach, the text-based approach, and the guided composition (Raimes, 1983). Basically, writing in product-based approaches has served to reinforce L2 writing in terms of grammatical and syntactical forms. There is a variety of writing activities in this approach which can raise students' awareness in second language writing from the lower level of language proficiency to advance such as the use of model paragraphs, sentence-combining, and rhetorical pattern exercises.

Writing in the product approach is viewed as a simple linear model of the writing process which proceeds systematically from prewriting to composing and to correcting (Tribble, 1990). However, Raimes (1983) found that product-based writing can in no way be described as linear or as neat as is generally believed:

Contrary to what many textbooks advise, writers do not follow a neat sequence of planning, organizing, writing and then revising. For while a writer's product - the finished essay, story or novel - is presented in lines, the process that produces it, is not linear at all. Instead, it is recursive. (Raimes, 1983: 229)

It is true that product based writing helps instructors raise learners' L2 writing awareness, especially in grammatical structures, but, there are also disadvantages highlighted in this form of approach. Writing with this format or view gives little attention to audience or the reader. As great emphasis is placed on the style of writing and the importance of grammar or impressive vocabulary, this style of documentation can be termed as orthodox. Learners tend to lack motivation as the format is too strict or restricts their imaginations and places more importance on writing tasks or language structures

\section{2- Process Approach:}

Process-based writing is viewed as the way writers actually work on their writing tasks from the beginning stage to the end of the written product. This approach is also viewed as an activity in which teachers promote the usage of imagination and encourages the readers to peel off the boundaries they have set on their ideas. Bounce is given to the exploration of new thoughts. It is less of a grammar exercise and more of a way to aid ones mental creativity. The five-step writing process model is used.

a)

\section{Prewriting:}

Teachers will provide a writing task which will enable the learners to exercise their brain cells. Through mind jogging effective or appropriate words can be listed. Discussions can brighten the ideas of the learners and improvement of thoughts can take place. This will lead to the piece to be accurately written.

\section{b) First draft composition:}

Learners will use whatever they could muster from the group discussions. This includes efficient vocabulary and ideas gathered by the learners.

\section{c) Feedback:}

In this writing stage, learners will receive comments from real audiences which can be a writing teacher or their peers and move on to new ideas in another draft.

\section{d) Second draft writing:}

Based on the comments of teachers and peers, learners will modify their previous draft by revising, adding, and rearranging ideas.

\section{e) Proofreading:}

In the final stage, student writers will not only discover new ideas and language forms to express their ideas in writing but also will realize the importance of vocabulary and effective communication with one's peers in drafting an impressive piece of writing.

Through the writing process, professional writers or even students hardly follow the fixed sequence of writing stages linearly because they have to move back and forth among different writing steps in order to come up with better ideas. This idea is supported by Scott (1996).

Writing processes may be viewed as the writer's tool kit. In using the tools, the writer is not constrained to use them in a fixed order or in stages. And using any tool may create the need to use another. Generating ideas may require evaluation, as may writing sentences. And evaluation may force the writer to think up new ideas. (Scott, 1996:155)

The process approach in conclusion is diverse and unpredictable (Tribble, 1990) while writers try to redefine their ideas and approximate the meaning of what they want to express in their work. Process-based approaches have numerous advantages so it is a well known tool for instructors. The improvement in the writing process is a step by step method. Through the aid of instructors the learners generate proper feedback and 
through individual attention the learners get the chance to experience an exclusive and effective way towards the betterment of their writing style.

In spite of being widely used in ESL /EFL context, the major drawback of process-based writing is that the learners have to spend quite a long time to complete one particular piece of writing in the classroom which is not practicable in reality. Hence, the effective usage of time isn't emphasized upon.

\section{3- Genre Approach:}

The genre approach combines an understanding of genre and genre teaching together in the writing class. It can also be called "English for Academic Purposes approach" (Silva, 1990:17).

Writing in the genre-based approach is regarded as a sub body of the product-oriented approach since learners have an opportunity to study a wide variety of writing patterns, for instance, the business letter, the academic report, and the research paper. Like other writing approaches, the genre-based approach is increasingly used in the L2 writing classroom due to having certain strengths. The focus of writing in this approach aims to integrate the knowledge of a particular genre and its communicative purpose.

Learning to write is part of becoming socialized to academic community finding out what is expected and trying to approximate it....The reader is a seasoned member of the hosting academic community who has well-developed schemata for academic discourse and clear and stable views of what is appropriate. The text is a more or less conventional response to a particular task type that falls into a recognizable genre. (Silva, 1990: 16)

Thus, learning specific genre can be considered as a way to help learners come up with appropriate actual writing in their real life outside the classroom. It also increases learners' awareness of such writing conventions as organization, arrangement, form, and genre. Through the composing process genre-based writing reflects a particular purpose of a social situation and allows students to acquire writing skills consciously by imitation and analysis of each writing genre.

The limitation of the genre-based approach is that learners may not have diverse knowledge or have an effective word bank. Hence, hindrances shall arise in effectively communicating the idea to the readers. Another weakness is that the genre approach undervalues the writing skills which learners need to produce a written product and ignores the writing abilities learners have in other areas.

\section{The Importance Of Using An Integrated/Eclectic Approach In The Writing Classrooms:}

The strengths and weaknesses of each writing approach described in the previous section show that the three approaches go hand in hand. Genre, product, and process should be used as a combination to develop a model to teach and improve students' L2 writing. To integrate each approach in the writing class, teachers may follow the following steps. Teachers should start teaching writing with one approach and then adapt it by combining the strengths of other approaches in the writing classroom. Teaching the writing approaches separately very often results in unbalanced L2 writing performance. Therefore, using the integrated approach in the classroom has the main purpose of enabling learners to transfer the skills they have gained from each approach naturally from one mode to another and thus to produce their writing tasks efficiently. As Silva (1990) says:

In social interaction a knowledgeable participant can create, by means of speech, supportive conditions in which the novice can participate in, and extend, current skills and knowledge to higher levels of competence. (Silva 1990:31)

\section{Needs Analysis Of Language Learners:}

Richards (1990:2) identified three purposes of needs analysis:

1. Providing a mechanism for obtaining a wider range of input into the content, design, and implementation of a language program through involving such people as learners, teachers, administrators, and employers in the planning process.

2. Identifying general or specific language needs that can be addressed in developing goals, objectives, and content for a language program.

3. providing data that can serve as the basis for reviewing and evaluating an existing program.

It is the third purpose which is of concern here, reviewing and evaluating an existing program. Existing programs have established goals designed to meet the needs of their students. These goals are relatively permanent and determine the aims of the course. Needs analysis, however, can identify objectives, which are intended as sources to achieve the goals. In other words, as Brown (2001:36) states, "needs are not absolute, that is, once they are identified, they continually need to be examined for validity to ensure that they remain real needs for the students involved." Many good teachers conduct their own informal needs analysis in their classrooms, but it is a sign of a good language program that routinely conducts needs analysis on a programwide level.

Various sources of information can be accessed to carry forward a needs analysis, the first one being the students themselves. Learners, however, are not always an effective or reliable source of information in a 
Needs Analysis of Second Language Learners with particular regard to their Writing Skills

needs analysis, but they indeed constitute one of many possible sources; others according to Long (1980:15) are, "experienced teachers and graduates of the program concerned, employers, subject-area specialists, and written sources." Long (1980) also believes that in many cases learners, even experienced workers/learners, are not fully aware of their language needs, thus the learners' self-perceptions of their needs are not that reliable.

The most common method of conducting a needs analysis is through a questionnaire survey, it allows the researchers to gather much data in the most efficient way possiable. But as with the learners' limited selfawareness of their language needs, questionnaires also have some weaknesses. The researchers cannot be certain whether the data truly reflects what the respondents actually undergo. The problem lies in understanding whether the responses are what it is that they actually do, what they think they do or what they think the researchers want to hear.

In an effort to overcome these weaknesses, Long (1980) emphasizes triangulation, comparing different sets and sources of data. This can include triangulation of sources, e.g. students, teachers, employers; triangulation of methods, e.g., questionnaires, interviews, observations; or triangulation of investigators, e.g., self-observer, peer-observer, outside observer.

Irrespective of its shortcomings, needs analysis is a powerful tool to understand students' needs and to help the implementation of educational policies in the most effective way possible. In recent years, language teaching is more learner-oriented. Therefore, every subject or idea generated goes back to the learner himself. How his learning experience or his learning objectives pan out is based upon his resources and his capability to learn or ability of grasping new ideas. "[E]everything starts from him and everything goes back to him. It is not merely in relation to him, but with him, and depending on his resources that his learning objectives will be defined, that the methods of judging when and how they have been attained will be selected, and that a curriculum of learning will be made available to him." (Richterich and Chancerel 1980:4-5) In conclusion, the needs of the learners have to be taken under consideration. The current patterns or formats need to be customized according to the requirements of the learner. It has to be an experience which enhances the learner's capability of writing an impressive piece while effectively pampering the mental objectives revolving around it .

\section{Research Design}

\section{Research Methodology}

The current research is designed to study writing needs of the learners. Relevant research tools would used to understand their linguistic requirements, objectives, resources available and some of the psychological factors which may affect their learning.

\section{Population and Sample}

A total of 15 students, enrolled in grade 7 at Pak Grammar School Canal Bank Lahore, Pakistan, will be selected for the study.

\section{Procedure/ Method}

Descriptive research involves collecting data in order to test hypotheses or answer questions concerning the current status of the subject of the study. Descriptive data are typically collected through a questionnaire, interview or observation. Thus, the current research will adopt a descriptive method undergoing the procedure of: 1) selecting sample of population, 2) collecting information through questionnaires and 3) synthesizing findings based on the collected data in order to gauge the current status of learners' writing needs.

\section{Data Collection:}

\section{Sampling Technique}

The sampling technique that the researcher will adopt is that of a cluster random sampling. The cluster is already available that is a set of middle-class students of one of the high schools situated in Lahore. Among this cluster a random sample of 15 students ( $7^{\text {th }}$ graders) will be selected.

\section{Research Tools/ Instruments}

This research will be conducted around two major tools of research to explore students' needs in academic writing: 1) Questionnaire and 2) The Textbook.

\section{1- THE QUESTIONNAIRE: (attached in appendix)}

The questionnaire is the main source of data collection concerning students' writing needs, their reaction towards the content of the textbook and the teaching methods used. It would consist of sixteen questions (four pages) in total. The questions will mainly be closed-ended with options of yes or no. The questionnaire would also include open-ended questions. Closed-ended questions and open-ended questions will both be used due to the practicality and limitations that each type of question has. While open-ended questions will allow the researcher to receive "unexpected answers" (Brown, 2001:36), closed-ended questions provide 
Needs Analysis of Second Language Learners with particular regard to their Writing Skills

more uniformity so that the researcher will be able to get more clear information on what can be found to be in common among a broader range of students.

The questions will be divided into two parts. The part I would be designed about "general information" regarding writing activities and teaching techniques applied in their classroom. Moreover, it will seek to draw general perception of the students about the purpose and significance of academic writing. The Part II is going to be based on the learners' "personal choices" of the writing components. (A sample questionnaire is attached in the appendix)

\section{2- THE TEXTBOOK:}

The second source of data collection would be the textbook to investigate whether the material used in the book meets the students' needs in academic writing or not. The director of the school is the person who selects textbooks for every grade. The textbook being used in Pak Grammar School for class seven is the Book 7 of Oxford series entitled, "Oxford Modern English", written by Nicholas Horsburgh. It was published in 2000 in New York, Oxford University Press and printed in Karachi, Ibn-e-Hassan Printing Press Pakistan. The principal of the school under investigation stated that Oxford Series of Modern English is being used as a regular syllabus in more than $35 \%$ schools of Lahore.

\section{QUESTIONNAIRE DATA ANALYSIS: \\ Results and Findings}

\section{Part I:}

15 students were given the questionnaire and the response rate was $100 \%$. Beginning with Part I, in answer to the first question which was about the students' fondness of writing activities 11 out of fifteen said 'very much' and 4 of them marked 'yes'. It shows the high rate of students' interest in writing tasks. In the second question all the 15 students agreed that the purpose of these activities is 'both' preparation for exams and practice for real life communication. It expresses a $100 \%$ response of students' satisfaction in terms of writing practice done in their classroom.

In the third question, which was related to the effect of other language skills on writing, 8 students believed that 'reading' has the strongest effect on writing, 5 thought 'listening' and 2 agreed 'speaking' (See figure 1). In the space given for the reason of their choice, they tried to justify their answer. The ones who said it's reading they mostly believed that reading provides us with new information and also helps us in viewing the right expression of ideas. That's why, the more we read, the better we can write. Then, the students who said that the strongest effect is of 'listening', they wrote that without listening to the instructor carefully and without comprehending what he's trying to convey the learners cannot express the subject matter effectively in writing. Thirdly, the supporters of 'speaking' held that fluency in speech automatically develops our writing skills and makes us confident enough to feel comfortable with writing tasks (and vice-versa).

The above analyzed data of question 3 shows that the students need an integration of skills in language classrooms. They are conscious of the fact that all the four macro skills are inter-connected and cannot be taught in isolation from each other.

The fourth question was meant to gauge the learners' linguistic sensibility, particularly, in terms of writing components. They were asked to identify the techniques that are required for effective academic writing. $100 \%$ participants marked all the four elements given in the options (grammar, expression, organization and vocabulary). It advocates that the writing teachers must focus on all these areas which the students themselves feel are crucial to their writing competence.

In answer to the fifth question which was about the teaching style that is followed in their classroom, all the students marked the same option i.e. 'teacher-student interaction' while doing written work specifically. This is a good indication which shows that the teacher is concerned enough to extract time for conferencing with every student individually in the class.

However, the students' response to question 6, which was based on the 'feedback' that they receive from teacher, sounds dissatisfactory. Six students said that they get a written feedback, four get oral and five do not receive any kind of comments from teacher (See figure 2). This diversity in the learners' answers indicates an imbalanced treatment of the teacher in class. Moreover, it also reveals the instructor's incapability of error management in the students' work.

In question 7, asking about the improvement of other language skills through writing, for option $\mathrm{i}$ (speaking) 10 students said YES and 5 marked NO, for option ii (listening) 9 answered in YES and 6 in NO and for the third option (reading) all the 15 students said YES. So the average rate of $75 \%$ students saying YES demonstrates the significance of writing for the development of other language skills (See figure 3).

Question 8 was an open-ended one in which the students named writing activities usually done in their classroom. The students came up with many tasks that were all derived from different approaches. The responses included controlled to free all kinds of writing activities. In the next question which was the last 
question of part I, all the learners agreed these activities generate interaction in class, thus can fairly be called communicative in nature.

\section{Part II:}

Part II of the questionnaire was meant to draw an overall measurement of the learners' 'personal choices' which make the 'needs analysis' easier for the researcher. The first question in this section was designed to determine the students' weak areas in writing. In the first option all the fifteen students believed that they are weak in 'vocabulary'. For the 'grammar rules' 12 of them said YES and 3 answered in no. And for the 'expression and organization of ideas' only one marked NO and the rest of fourteen students thought that they need to learn it more for a better writing ability (See figure 4).

The second question contained a list of different types of writing, in which the students had to tell for each type whether they like it or not. For instance, about 'creative writing' 14 students said YES and 1 said NO. For 'letter/ application' there were $10 \mathrm{YES(es)}$ and 5 NOs. As far as 'comprehension/ question answer exercises' were concerned 6 students liked them and 9 disliked. Twelve students were fond of 'summarizing a text' and three were not. All the students liked to do 'research-based writing' and only four supported 'translation exercises' (See figure 5). It reveals that the learners mostly enjoy doing free and less-controlled writing which involves a process of revising, editing and re-drafting.

In answer to question 3 only two students chose to work 'individually', 9 wanted to work in pairs and 4 liked 'groups' (See figure 6). It shows that the majority of students enjoy working with other classmates because it gives them opportunity to communicate and discuss things with each other. The next question was about the learners' choice of receiving 'feedback' from teacher and all of them desired to get it 'always' on their written work.

The last three open-ended questions presented in-depth answers by the students. In their choice of the 'tests' most of them expressed ways of being tested beyond the text, such as essay writing, story-making and research projects etc. In the next question based on the problems they have in writing, most of the students had issues related to grammar, form and structure and vocabulary. In the last question asking 'suggestions for improvement', the students came up with very interesting and intelligent ideas, some of them are quoted below:

1- "The teacher should give us an unseen topic in the end of every class to write about it. It will help us in using our knowledge about things and write it on a paper any time without preparation." (Sana Saleem)

2- "Teachers should show us visuals and then should ask us to write anything about it that we want to write and also in such writings the teachers should not point out mistakes. It will help us in writing openly whatever we want to write." (Alisha Aftab)

3- "The teachers should show us some good writings so that we can see what is the right way of writing and how should we organize ideas." (Mehreen Mubashir)

4- "Me and my friend are weak in grammar we want that our teacher should revise the tenses everyday in class for 10 minutes. It will help us." (Saima Nawaz)

5- "I have a problem in reading from the book in front of other class members. I feel if the teacher will ask me to read something in class which I have written myself it would be easier for me to do that." (Madiha Fraz)

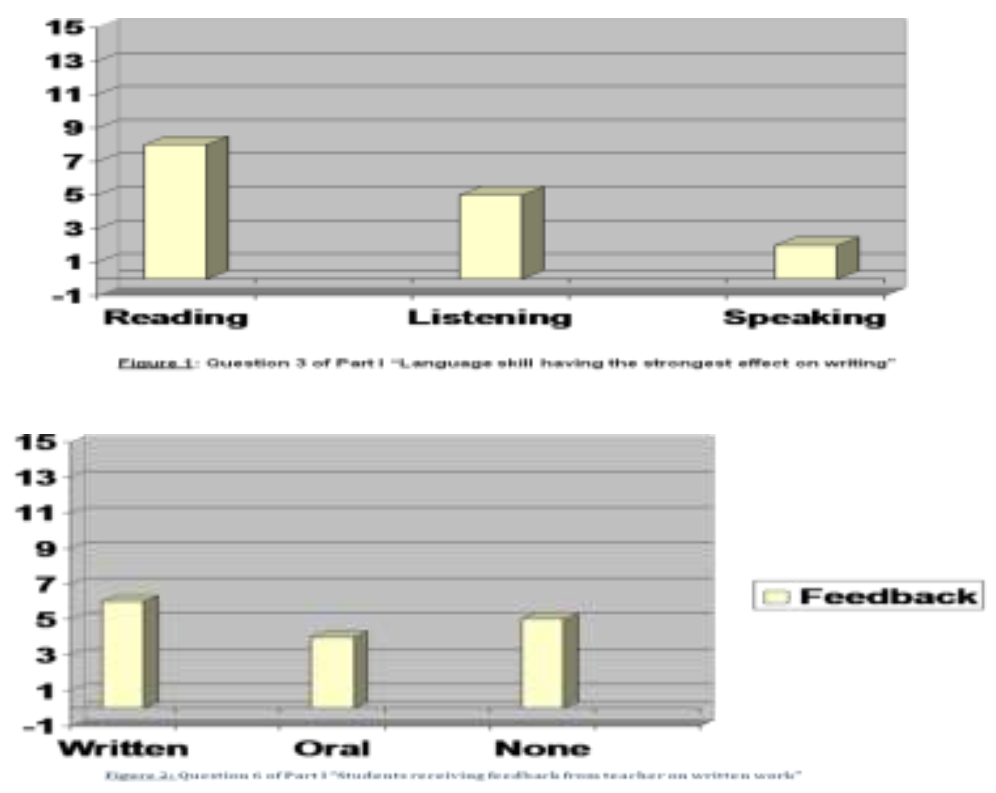



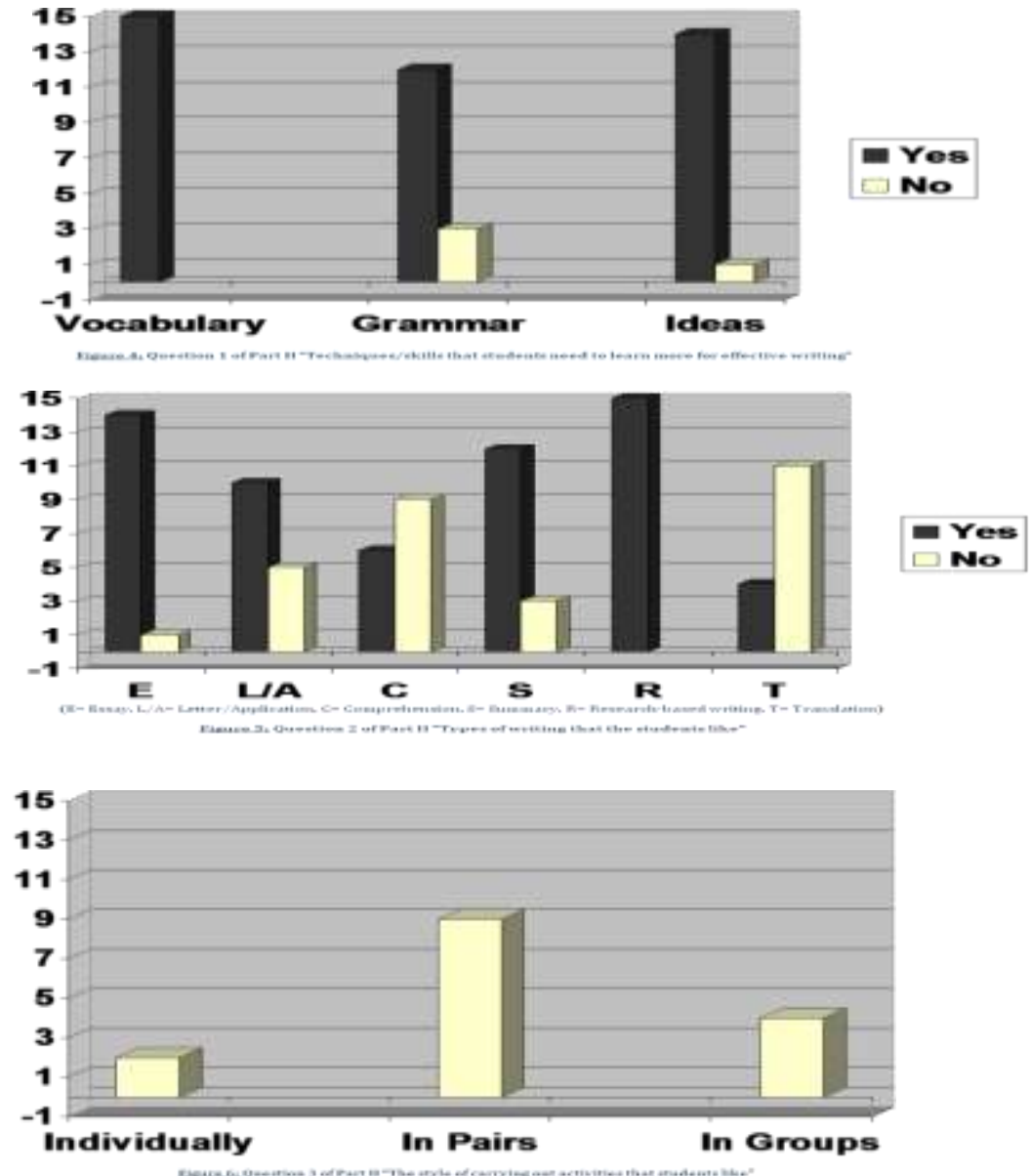

\section{Discussion}

\section{EVALUATION OF THE TEXTBOOK REGARDING LEARNERS' WRITING NEEDS:}

The textbook of the seventh graders, "Oxford Modern English" was employed as an instrument for research to investigate whether the material used meets the students' language needs in the class or not.

\section{1- Design:}

The book consists of eleven poems, twelve short stories and one play. It follows a systematic design that every exercise in the end of the text is divided into three major parts: 1) Comprehension, 2) Vocabulary and 3) Grammar.

\section{2- Approach:}

Two kinds of writing approaches become prominent while examining the exercises in the book. Some questions are centered on the product-focused writing and some of them emphasize process-based work. For instance, comprehension exercises typically follow product approach in which the students have to 'familiarize' the text first, then begin to answer the listed questions in which the starting questions are purely 'controlled' and text-based, while the following questions require 'guided' answers and the last question is mostly asking for 'free writing' such as expressing the student's own personal view of a phrase or image given in the text. The process approach is visible in questions like "write a short composition about what you think of hunting as a sport...give reasons for your views" (Textbook, pg. 4). This kind of a work makes the student revise and edit his/her work before writing the final draft.

However, some of the questions in the book present a combination of product and process approaches. For example, 'writing a poem on autumn' (Textbook, pg. 25) is a product-oriented activity which seeks to produce a particular outcome (poem on "autumn"), while it involves a process of adding and eliminating elements for redrafting the student's work simultaneously.

\section{3-Activities:}

Moving back to the findings of questionnaire, in question 2 of the second part it was explored that the students are mostly fond of writing activities that are less-controlled in nature. Looking at the textbook one 
Needs Analysis of Second Language Learners with particular regard to their Writing Skills

observes that the exercises contain a variety of all types of tasks. For example, students are asked in most of the vocabulary developing activities to use the given words or phrases in sentences of their own. Similarly, they are sometimes given a list of words to look them up in the dictionary (Textbook, pg. 4). These kinds of tasks are typically controlled in nature. Whereas, in the same exercises some questions are based on guided activities such as identifying adverbs in sentences and stating what verbs they qualify or completing the statement by using an adverb beyond the text (pg. 5). Apart from these, every exercise includes a practice for free-writing also. For example, students are asked to write a paragraph on the main idea of the text, compose a poem on their own or write a note on what they feel is the actual concern of the writer in the text etc.

However, these activities cannot as such be called communicative, for they are all designed for individual practice. Students are not given a room for interacting with each other while doing the writing tasks. This aspect hinders the capability of the textbook in meeting the learners' need for communication. But according to the data collected through questionnaire, the students believed that the writing work done in their class does generate interaction among themselves while working in pairs and groups. It reveals that the teachers who do not depend upon syllabus designers can possibly make space for discussion in class and transform noncommunicative activities into communicative ones.

Nevertheless, the tasks given in the textbook are authentic in nature; for they are structured around real life situations such as using a dictionary to look up words, replacing grammatical patterns in sentences with reference to the context and most particularly creative writing on daily life items or actions.

The standard of activities parallels the comprehension level of seventh graders. There are some tasks which help the teacher in eliciting the learners' prior knowledge (schema), such as writing a short poem on one of the given topics after noting down all the information that the students already have about it (Textbook, pg. 7). Moreover, the activities in the book do not exhibit any kind of cultural gaps for the students as the topics are either based on natural objects or human beings in general.

In their response to question 1 of part 2 in the questionnaire, the learners' expressed that they need practice in the four major areas of writing: vocabulary, grammar, expression and organization of ideas. In their textbook, each reading passage is followed by two sets of exercises. The first section includes comprehension questions, vocabulary extension, sentence building and composition. While the second section places its emphasis on the use of structures, phrases, punctuation and questions dealing with grammar. This design meets the learners' requirement of vocabulary and grammar instruction. For the fulfillment of the rest of two elements that are expressing ideas and organizing content, the students get enough practice in the section of creative writing.

All the activities involve reading and writing skills and most of them integrate the two, while listening and speaking are constantly being ignored. There is no task in the book which is intended to develop the learners' listening or speaking skills that the students themselves feel are crucial for the improvement of writing (questionnaire finding).

Despite its very few limitations, "Oxford Modern English" presents a good course for the students. Tasks and topics sound interesting and attractive for the learners. A variety of approaches and types of writing suit the practicality of the subject, for it's not possible for a class to follow one single approach for effective language learning.

\section{Recommendations}

It seemed that students are basically receiving what they would like to receive from the class. However, there was a gap between students and instructor in some of the needs in academic writing. One example was about the amount of feedback from the instructor. Some students said that they receive enough oral or written feedback from the teacher, while others do not, and stated that they would like to receive it on their written work "always". These findings suggest that the teachers need to be aware of what the students need or want from their teaching style to meet the needs of the class in a better way.

Moreover, it was discovered in the students' suggestions that they have a desire for exposure to reading model pieces of writing. Thus it is recommended that the learners should be shown good expressions in writing, so that they can read it and grasp the knowledge of techniques that improve one's written performance.

The two major flaws in the textbook: 1) non-communicative nature of activities and 2) lack of practice for speech and listening competence can both be resolved through an effective mode of instruction. The application of a communicative approach in teaching will make the learners work together and will also give them an opportunity to listen and speak while carrying out tasks in class.

Credibility of learners as a source for needs analysis greatly increases if they are aware of their own needs. However, as stated before, many of the students are still in the early stage of their academic life, and might not be aware of their own needs. So, it is also important that teachers should make their learners conscious of what they need to learn. This could be achieved by regularly conducting a Needs Analysis in language classrooms on a small scale every month. 


\section{Conclusion}

Teaching writing skills to non-native students is a very challenging task for teachers because developing this skill takes a long time to see the improvement. In addition, teaching separate writing approaches in the writing class does not fit in a second language context since the weaknesses of each writing approach tend to impede students' writing development. Therefore, writing teachers need to incorporate the insights of the different approaches and apply an integrated/eclectic approach into the writing class for teaching second language learners. The strengths of one approach can complement the other. Moreover, a combination of approaches will make space for the integration of language skills automatically. It will also apply communicative techniques in the classroom and will help the teachers to develop learners' writing competence by providing appropriate input of knowledge and skills in the writing procedure.

It is fairly apparent now through the current research that 'needs analysis' does give valuable information for teachers and linguists to understand the learners' needs and attitude towards the target language. As mentioned earlier that the questionnaire and analysis of the textbook was meant to elicit the learners' linguistic needs, objectives, their available resources, and some of the instructional factors affecting their language learning, which was all successfully achieved in the study. The result of the analysis will be helpful in understanding the characteristics of the learners and will also be useful for policy makers, curriculum planners, material designers, language teachers, teacher trainers and those who are interested in the field.

\section{References}

[1] Abisamra, N. S. (2001). Effective Writing. Retrieved from http://nadabs.tripod.com/writing/

[2] Brown, J. D. (2001) "Using Surveys in Language Programs”, Cambridge: Cambridge University Press.

[3] Long, M. H. (1980) "Methodological issues in Learner Needs Analysis", Long, M. H. (Ed.), Second language needs analysis. Cambridge: Cambridge University Press.

[4] Omaggio, H. A. (1993) "Teaching language in context”, Boston: Heinle \& Heinle Press.

[5] Raimes, A. (1983) "Techniques in Teaching Writing", Oxford: Oxford University Press.

[6] Richards, J. (1990) "The Language Teaching Matrix", Cambridge: Cambridge University.

[7] Richterich R. and Chancerel J.L. (1980) "Identifying the Needs of Adults Learning a Foreign Language", New York: Pergamon Press.

[8] Scott, V.M. (1996) "Rethinking Foreign Language Writing”, Massachusetts: Heinle and Heinle Press.

[9] Silva, T. (1990) "Second language composition instruction: Developments, Issues, and Directions in ESL", Kroll, B. (Ed.) Second Language Writing: Research Insights for the Classroom. (pp.11-36). New York: Cambridge University Press.

[10] Tribble, C. (1990) "Writing" (pp.37-44), Oxford: Oxford University Press. 